\title{
Prve literarne pravljice francoskega salonskega vala: hibridna žanrska zVrst
}

\author{
Lilijana Burcar
}

Filozofska fakulteta v Ljubljani, Aškerčeva 2, 1000 Ljubljana

https://orcid.org/0000-0002-1135-9671

lilijana.burcar@ff.uni-lj.si

\begin{abstract}
Del ideološke zapuščine romantičnega 19. stoletja je prepričanje, da naj bi pravljice odsevale motiviko ljudskih pripovedi. Literarnozgodovinska veda dokazuje, da so pravljice hibridna literarna zvrst, ki je vzniknila v okviru francoskega salonskega gibanja ob koncu 17. stoletja. Salonske pisateljice, ki so bile nosilke novega žanra, so se skupaj s Perraultom naslonile na že obstoječe literarne predloge predstavnikov renesančne novele in srednjeveškega viteškega in pastoralnega romana. Iz žanra renesančnih novel so prevzele narativni prijem okvirnih pripovedi, v katerih so opisovale salonsko okolje in pripovedne načine, na katere so nastajale nove pripovedi, ki so jih okvirile še drugače. Vsako pravljico so opremile s posvetilom in uvodom, na koncu pa še s pojasnilom, največkrat v obliki opombe, pri čemer so predstavile svoja teoretska razmišljanja in literarne vire, po katerih so se zgledovale. Iz žanra srednjeveškega viteškega in pastirskega romana so prevzele arhetipskost aristokratske dvorne kulture in neotiplivost prostora in časa, ki ga podčrtuje družbena nezaznamovanost, kar je pravljicam dalo pečat tipske statičnosti. Tem predelavam in dopolnitvam literarnih predlog zgodnejših obdobij so dodale še elemente magičnega, ki so si jih izposodile deloma iz antične mitologije in deloma iz čudežnih pripovedi, značilnih za ljudsko pripovedništvo, s poudarkom na vilah in njihovi magični moči.
\end{abstract}

Ključne besede: literarne zvrsti / romantika / pravljica / hibridni žanr / viteški roman / pastoralni roman / novela / magično

Romantično gibanje 19. stoletja je prineslo prepričanje, da naj bi literarne pravljice $\mathrm{v}$ celoti izhajale iz ljudskega izročila in se napajale z motiviko ljudskih pripovedi. ${ }^{1}$ Zato naj bi bile po vsebini in strukturi pradavne oziroma vzporedne ljudskemu izročilu, saj naj bi v zapisani obliki zgolj prenašale bogato zakladnico ljudskih motivov in na

${ }^{1}$ Članek je nastal v sklopu raziskovalnega programa »Medkulturne literarnovedne študije«, št. P6-0265, ki ga sofinancira Javna agencija za raziskovalno dejavnost Republike Slovenije. 
drugačen način podajale, $s$ tem pa nadaljevale in ohranjale tradicijo ljudskega pripovedništva (Grimm in Grimm 5-26; Treverson 61-63; Zipes "Media-Hyping" 272). Tako kot ljudske pripovedi naj bi tudi literarne pravljice po pripovedni motiviki in obliki izpričevale skupno in pradavno kulturno preteklost, $s$ tem pa domnevno enovito pripadnost sicer povsem različnih skupin in razrednih slojev ljudi, združenih v nov tip države, v t. i. nacionalno državo 19. stoletja (Haase, "Yours« 384-385; Snyder, "Cultural« 35). V skladu s tem ideološkim prepričanjem naj bi prvi avtorji literarnih klasičnih pravljic, začenši s Charlesom Perraultom kvečjemu zbrali in priredili ljudske pripovedi v evropskem prostoru oziroma posegli vanje le toliko, kolikor naj bi bilo treba pri njihovem prenosu iz ustne oblike sporočanja v pisno (Zipes, When 73-76; Treverson 62). Pri tem naj bi bile zapisane in avtorsko domnevno le minimalno preoblikovane pripovedi že od nastanka $\mathrm{v}$ 17. stoletju namenjene najmlajšemu bralstvu in poslušalstvu. Literarna zgodovina je te postulate začela prevpraševati že v prvi polovici 20. stoletja. Sistematično pa jih je ovrgla v drugi polovici, pri čemer je vodilno vlogo prevzela anglosaška veja literarne zgodovine. ${ }^{2}$

Literarne pravljice so prepoznavna "družbeno-literarna" zvrst (Thelander 465), nastanku katere je botroval sklop specifičnih družbenopolitičnih okoliščin. Kot umetna zvrst z značilnim naborom struk-

${ }^{2}$ Prelomno delo na tem področju sega v leto 1934, ko je Mary Elizabeth Storer ponovno zbrala, uredila in pri založbi Columbia University v New Yorku objavila nekaj najbolj reprezentativnih rokopisov prvih literarnih pravljic pod naslovom Contes des fées $d u$ grand siécle, večinoma vodilnih avtoric francoskega salonskega gibanja, na primer Mme d'Aulnoy, Mlle Bernard, Mme de Murat in Mlle de La Force (Welch 11). Naslednji preboj je sledil v sedemdesetih in osemdesetih letih 20. stoletja, ko je anglosaška literarnozgodovinska veda leta 1969 postregla z disertacijo Melvina Delmarja Palmerja o literarnem opusu Mme d'Aulnoy in njenem vplivu v Angliji v zgodnjem 18. stoletju. V osemdesetih pa so to področje literarnih odkritij zaznamovale literarnozgodovinske razprave Lewisa Seiferta, Ruth Bottigheimer in Jacka Zipesa (Jones 239). Naš jugoslovanski prostor je bil prav tako v ospredju tega preboja, kar med drugim dokazuje prevod izbranih pravljic Mme d'Aulnoy, ki ga je Mladinska knjiga kot del zbirke pravljic in pripovedk Zlata ptica v prevodu Tadeje Krečič objavila leta 1987 pod naslovom Pavji kralj in druge pravljice. V uvodu te zbirke sedmih izbranih pravljic ("Princ Škrat", »Pavji kralj«, "Zlata vejica«, "Dobra miška«, »Drobtinica Pepelka«, "Srečna" in "Igračka") beremo: "Pravljice gospe d'Aulnoy ostajajo med najbolj avtentičnimi mojstrovinami pravljične književnosti. Najrajši je zasnovala pripoved $\mathrm{v}$ obliki romanesknega zapleta in ni oklevala, kadar je pod plaščem alegorije razkrivala tisto, kar je v njenih očeh predstavljajo najhujšo socialno krivico: prisilno poroko. In prav tako kakor v resničnosti tistega časa se v njenih pravljicah večkrat zgodi, da se stvari končajo slabo: lepi princi se ne morejo vedno poročiti s svojimi ljubljenimi princeskami« (Touttain 7). 
turnih in motivnih značilnosti so se pravljice ali to, kar danes razumemo kot klasične literarne pravljice, pojavile šele ob koncu 17. stoletja kot del t. i. francoskega salonskega gibanja, ki so ga vodile elitne aristokratske ženske blizu dvora Ludvika XIV. (Hannon in Duggan 378-379; Zipes, "The Rise« 2). Nastanek literarnih pravljic in njihova uveljavitev kot specifični žanr sta bila neposredno povezana z zagovorom aristokratskega družbenega reda, njemu pripadajočih družbenih norm in omike, kar je bilo v ostrem nasprotju z interesi ostalega prebivalstva, še zlasti kmečkega življa (prim. Zipes, Breaking). Kot prepoznaven, od ljudskega pripovedništva vseskozi povsem ločen in tako po strukturi kot motiviki pravzaprav diametralno nasproten žanr, so se uveljavile kot sestavni del salonskega pripovedništva, namenjenega druženju in edukativni zabavi aristokratskih krogov v zadnji četrtini 17. stoletja, še zlasti med aristokratinjami, ki so bile tudi njegove izumiteljice (prim. Seifert, Fairy). Prve literarne pravljice so bile namenjene izključno odraslemu krogu bralk in bralcev ter poslušalk in poslušalcev, ki so obiskovale_i salone, saj so poleg zagovora aristokratske družbe in njenih pravil obnašanja prvenstveno združevale vrsto izrazito družbenopolitičnih konotacij. Te so avtorice (skupaj s pridruženimi jim avtorji) skrile pod krinko domnevno le predelanih in zatorej neškodljivih ljudskih pripovedi, da bi se izognile cenzuri (Brocklebank 128; Hannon in Duggan 380). Pravljice francoskega prvega vala so služile kot politično orodje v rokah salonskih pisateljic, saj so ga uporabile v zagovor pravic žensk njihovega stanu. $Z$ njim so nastopile predvsem proti prisilnim porokam, medtem ko se je Charles Perrault $s$ pomočjo taistega žanra postavil na stran zagovornikov moderne, a hkrati tudi konservativcev $\mathrm{v}$ t. i. sporu glede žensk.

Avtorice (in avtorji) prvih literarnih pravljic so resda črpale tudi iz ljudskega pripovedništva, vendar so se pri zasnovi te nove literarne zvrsti primarno naslonile na obstoječe literarne zvrsti in osrednja dela njihovih vodilnih predstavnikov, njihove strukturne in motivne značilnosti pa so prepletle v novo literarno zvrst književnih pravljic. Poglavitni vir neposrednega navdiha sta bila poleg grške mitologije in antične rimske književne zakladnice, vključno $\mathrm{z}$ basnimi in fantastičnimi pustolovskimi romani (npr. Apulejeve Preobrazbe), še dva izvorno izključujoča se žanra. To je bila pozna srednjeveška novela na eni strani in na drugi srednjeveški evropski roman s svojima podzvrstema, pastoralnim bukoličnim romanom in viteškim romanom. Ljudsko pripovedništvo je pri tem odigralo sekundarno vlogo. 


\section{Temeljna podstat pravljičnega žanra: poznosrednjeveška novela in viteški ter bukolični roman}

Obe zvrsti, poznosrednjeveška novela in srednjeveški roman, sta ključno zaznamovali tako strukturne kot vsebinske prvine prvih literarnih pravljic. Njihove avtorice (in avtorji) so se tako v strukturnem kot vsebinskem pogledu zgledovale po delih renesančnih mojstrov novelističnega pisanja. To so bili Dekameron (1353) Giovannija Boccaccia, Prijetne noči (Le Piacevoli Notti, 1550-1553) Giovannija Francesca Straparole in Zgodba vseh zgodb ali Il Pentameron (Lo cunto de li cunti, 1634-1636) Giambattiste Basileja. Izraz novela izhaja iz latinske besede novus ali nekaj novega in je krajša jedrnata pripoved, katere dogajanje je $\mathrm{v}$ nasprotju s pastoralnim in viteškim romanom postavljeno v novodobno in prepoznavno zgodovinsko in družbenopolitično okolje. Zaznamujejo ga značilne poteze vsakdanjega življenja bolj in manj premožnih slehernikov, s tem pa tudi nabor različnih osebnosti, njihovih značilnosti in vsakodnevnih tegob. Poudarek - od Giovannija Boccaccia in njegovega Dekamerona naprej - je na hudomušnih, satiričnih in drugih vrstah pripovedi in na anekdotah $\mathrm{z}$ nenavadnimi zasuki in zaključki, ki izvirajo iz lahkovernosti, pohlepa, nekrepostnosti in podobnih lastnosti vpletenih. Največkrat je v ospredju ljubezen, tako resna in vdana kot lahkoživa ali izdana, ki jo $\mathrm{v}$ večini primerov poraja nezvestoba zakoncev in je vir ironičnih, zabavnih in poučnih preobratov (Bottigheimer, Fairy Tales 267). V ospredju zgodb ali pripovedi, ki skupaj tvorijo zbirko novel, je - kot je vzorec začrtal Boccaccio - govor o "cerkvenih dostojanstvenikih in menihih, o plemičih in meščanih, o zvestih ženah in lahkoživkah, o praznoverju preprostih kmetov in sleparstvu menihov, o nebogljeni nevednosti in zdravi prebrisanosti« $s$ poudarkom na "moči naravne zvitosti in razuma" (Fatur 58).

Temeljna strukturna značilnost zbirk novelističnih pripovedi Boccaccia, Straparole in Basileja, ki jo prevzamejo tudi salonske avtorice prvih literarnih pravljic, je njihova pripovedna okvirjenost. Vsako zbirko povezuje v celoto in jo tako okvirja temeljna, uvodna pripoved, ki je tudi krovna ali t. i. okvirna pripoved. Njena funkcija je ključnega pomena, saj preostalim pripovedim v zbirki podeljuje mimetično verodostojnost oziroma verističnost, tj. tukajšnjost in zdajšnjost. Okvirna ali krovna pripoved pojasnjuje, kdo so pripovedne osebe, ki so v skladu s pravili mimetične verodostojnosti ne le poimenovane, marveč so, še zlasti če gre za osrednje osebe, tudi povezane z obstoječimi in zgodovinsko prepoznavnimi osebnostmi takratnega časa. Pripoved, ki okvirja vse ostale, pojasnjuje tudi, od kod prihajajo, in predvsem zakaj so se v 
določenem prostoru na istem ali izbranem mestu znašli člani in članice združbe, ki si čas, ki ga morajo prisilno preživeti skupaj, krajšajo s pripovedovanjem zgodb. Krovna pripoved daje kontekstualni smisel vsem ostalim in jih povezuje v skupno celoto ali sestavljanko, ne glede na njihovo tematsko razpršenost. Predvsem gre za strukturni princip in literarni prijem, s katerim je Boccaccio (in po njegovem vzoru Straparola in Basile) preostalim fiktivnim pripovedim nadel pečat realnega: čas in prostor je bilo mogoče na ta način, $v$ nasprotju s pastoralnimi in viteškimi romani, zakoličiti in predočiti kot realni čas in prostor, ki ne obstajata v davni in neotipljivi, odmaknjeni viteški preteklosti, marveč tukaj in zdaj, sočasno z bralstvom (Bottigheimer, Fairy Tales: A New History 77). To je zbirkam pripovedi nadelo narativni pečat resničnosti, postavilo jih je v realni vsakdanjik in v neposredno geografsko bližino bralstva. V Boccaccievem Dekameronu tako iz okvirne ali krovne pripovedi izvemo, da je zbirka sto pripovedi rezultat druženja desetih mladih fantov in deklet: ti so se pred kugo, ki je leta 1348 razsajala po Firencah, zatekli na podeželje, kjer so si na varnem in $\mathrm{v}$ osami podeželskega dvorca deset dni krajšali čas s pripovedovanjem zgodb. ${ }^{3}$ Basile svojo veristično okvirjeno zbirko petdesetih pripovedi, poimenovano Zgodba vseh zgodb, postavi v Neapelj: prizorišče okvirne zgodbe je mestni trg, srčika urbanega vrveža, križišče poti in srečevališče najrazličnejših ljudi vseh stanov, kjer je mogoče slišati ne le različne govorice in profanosti, marveč $\mathrm{v}$ živo spremljati različne vrste obnašanja in slikovitih pogledov na svet. Basile pripovedniške vloge $\mathrm{v}$ nasprotju $\mathrm{z}$ Boccacciem in Straparolo ne zaupa premožnim, marveč najbolj deprivilegiranim, ki jih predstavlja skupina desetih žensk iz ljudstva, kot so na primer golšava Meneca, šepava Zeza, grbasta Popa, škilasta Paola in garjasta Ciommetella. Vse druži vidna deformacija ali manko, ki je posledica njihove prikrajšanosti. S tem Basile pripovedni zorni kot prestavi od uglajene gospode $\mathrm{k}$ revnim in siromašnim in odpira vrata neposrednosti, ki se med drugim kaže $\mathrm{v}$ profanosti jezika in seksualni eksplicitnosti zgodb (Bottigheimer, Fairy Tales: A New History 80).

Ta strukturni princip pripovednega okvirjanja in umeščanja zgodb, ki ga je v evropskem prostoru vpeljal Boccaccio, utrdila pa sta ga

${ }^{3}$ Straparola svojo skupino pripovednikov in pripovednic v zgodbi, ki okvirja vse ostale, podobno umesti na otok Murano v neposredno bližino Benetk, v palačo Ottavia Marie Sforze, nekdanjega škofa mesta Lodi in člana dinastije Sforza. Ta se med beneškim karnevalom z ovdovelo hčerjo Lucrezio Sforza Gonzaga in ostalo družbo zateče v svojo palačo, da bi ubežal političnemu pregonu in obračunu, ki ga pripravlja njegova opozicija v Milanu. Druščina si na varnem trinajst dni krajša čas s pripovedovanjem zgodb. 
Straparola in Basile, prevzamejo tudi salonske avtorice, saj prve literarne pravljice vpletajo v druge zgodbe, ki služijo kot posebna vrsta konteksta. Marie-Catherine d'Aulnoy, avtorica prve literarne pravljice in ena od najodmevnejših in najproduktivnejših salonskih avtoric, je na primer svoje tri pravljice "Le Mouton: Conte" (Oven), "Finnete Cedron" (Pepelka Drobtinica) in "Fortunée" (Sreča) ${ }^{4}$ podobno kot Basile, uokvirila dvojno. Besedilo, ki stoji na začetku tretjega dela v zbirki pravljic z naslovom Les contes des fées, je naslovljeno "Saint-Cloud: Conte" in rabi kot pripoved vseh pripovedi. V njej avtorica opisuje izlet v istoimenski kraj nekaj kilometrov od Pariza, kjer stoji razkošna poletna palača zakoncev Madame in Monsieur. To sta, kot je mogoče razbrati iz avtoričinega uradnega posvetila, ${ }^{5}$ drugi imeni za Charlotte-Elisabeth Bavarsko, drugo ženo t. i. Monsieurja ali Gospoda, brata Ludvika XIV. Pripoved uvaja tudi Madame $\mathrm{D}^{* *}$, kar je psevdonim za avtorico, torej d'Aulnoy: opisuje čas, ki ga preživi v izbrani aristokratski družbi, pripovedujoč zgodbe, ki si jih je zapisala v beležnico, da bi jih uporabila na srečanjih, kjer se tovrstne zgodbe bere oziroma pripoveduje naglas. Sledi novela z naslovom »Don Gabriel Ponce«, njeno dogajanje je postavljeno v Španijo, vanjo pa so umeščene tudi tri ločene pravljice. V zaključku nas besedilo vrne k začetni, okvirni zgodbi o nastanku in zapisovanju pripovedi (Bottigheimer, Fairy Tales Framed 168). Podobno besedilo Les lutins du château de Kernosy (1710) izpod peresa ene od vodilnih salonskih avtoric Mme Murat vsebuje tri pravljice; vse pa okvirja opisna pripoved o zabavi v enem od bretonskih podeželskih dvorcev. Tu zbrana aristokratska druščina preživlja večere tako, da se predaja iskrivim pogovorom, ki veljajo za svojevrstno umetnost. Ena od oblik preživljanja prostega časa je igranje posebne vrste kart: glede na karto, ki jo povleče gost ali gostja, mora ta zapeti pesem, povedati zgodbo ali pa uglajeno kritizirati že povedano zgodbo druge članice ali člana omizja, in sicer tako, da pove svojo ter z njo dopolni, nadgradi ali pa prekosi že povedano prvo verzijo (Welch 504). Ta okvirna zgodba Mme Murat, v katero so vgrajene tudi tri pravljice, odslikava (medtem ko zgoraj opisana okvirna zgodba Catherine d'Aulnoy na to namiguje), kako so v resnici nastajale in se oblikovale pravljice v salonskem okolju (Beale 76).

${ }^{4}$ Objavljene so bile v tretjem delu zbirke (od skupaj štirih delov) z naslovom Les contes des Fées (Zgodbe vil, 1697). V prvih dveh delih so samostoječe, opremljene s posvetili, uvodnimi pojasnili in zaključki, medtem ko so v tretjem in četrtem delu tudi narativno okvirjene in umeščene $\mathrm{v}$ druge prozne oblike pripovedi.

${ }^{5} \mathrm{~S}$ takšnimi vrstami razdelanih posvetil so salonske avtorice (in avtorji) pospremile vse svoje objave, saj so tako zavarovale svoja dela, sebe pa simbolično postavile pod patronat najvišjega aristokratskega sloja. 
V salonih, ki so jih vodile tudi same, so si namreč avtorice pripovedovale in izmenjevale pripravljene zgodbe. Te so - kot so zahtevala aristokratska pravila omikanega vedenja - podajale na način rafiniranega, tj. domnevno spontanega ali neprisiljenega, lahkotno igrivega in iskrivega načina govora, ki naj bi mimiciral vsakdanje, naravne oblike jezikovnega sporočanja (Feat 221-222). Skladno z aristokratskimi pravili obnašanja je tak način navidezno spontanega govora in podajanja zgodb pričal o omikanosti in uglajenosti aristokratinj, hkrati pa je tovrstni dialog dokazoval njihovo ustvarjalnost in razgledanost (Zipes, "The Rise« 32). To so namreč izkazovale tudi s popolnim preoblikovanjem že obstoječih in dobro poznanih literarnih predlog, še zlasti novelističnih pripovedi Straparole in Basileja, ali pa z vstavljanjem posameznih predelanih delov dobro poznanih pripovedi drugih avtorjev in avtoric najrazličnejših žanrov, pozneje pa lastnih vložkov, v izhodiščne predloge. Te naj bi prefinjeno in inteligentno osmislile ali osvežile ter izkazale ne le visoko stopnjo literarne razgledanosti, marveč tudi razpon lastne ustvarjalnosti (Seifert, »Marie-Jeanne« 77). V salonskih pripovednih izmenjavah, ki so bile zastavljene kot oblika inteligentne igre, so se avtorice in povabljenci hkrati seznanjali z deli in idejami drugih ter jih nadgrajevali in dopolnjevali z lastnimi vložki in razvijali različne, še vedno dopolnjujoče se koncepte na isto temo ali vrsto pripovedi. Zato ne preseneča, da so iz teh krogov izšle objave pravljic z istimi protagonisti in podobnimi motivi različnih avtoric in avtorjev (Jasmin 43). Znano je, da sta Charles Perrault in Catherine Bernard, ki sta se udeleževala istih salonskih srečanj, skorajda istočasno objavila vsak svojo verzijo pravljice "Grbavec s čopkom «, pri čemer datumi dovoljenja za objavo rokopisov pričajo, da je C. Bernard svojo verzijo ustvarila ali pa vsaj spisala pred Perraultom (Bottigheimer, Fairy Tales Framed 156).

Druga oblika okvirjanja pravljičnih pripovedi, poleg narativne, se nanaša na dejstvo, da so bile tudi vse samostoječe pravljice opremljene z dodatnimi pomožnimi besedili. Ta so pravljico uvedla in jo največkrat tudi zaključila. Gre za t. i. paratekste, ki so pravljico okvirili na svoj, tudi teoretično pojasnjevalni način, ob zaključku salonske literarne epohe in novih ponatisih ali prevodih del v drugi polovici 18. stoletja pa so bili odstranjeni. In sicer predvsem zato, da bi se ustvarilo in obdržalo vtis, da so prve literarne pravljice le prepis in trajni zapis ljudskega pripovedništva (Bottigheimer, Fairy Tales Framed 5). Pri tej tehnični obliki okvirjanja samostoječih pravljic gre za predgovore in uradna posvetila, ki stojijo na začetku in uvedejo pravljico, in za opombe ali pripombe, ki sledijo zaključku. Pravljice pa so največkrat opremljene 
še z vmesnimi komentarji, $s$ katerimi avtorica/avtor na ključnih mestih posega $\mathrm{v}$ besedilo in se, obračajoč se neposredno na bralstvo ali pa na osebo, kateri je besedilo posvečeno, ukvarja z ironično ali pa resno analizo svoje pripovedi, kot na primer Marie-Jeanne L'Héritier v pravljici "Diskretna princesa", za katero je motiv prevzela od Basileja in njegove pripovedi Sapia Liccarda (Bottigheimer, Fairy Tales Framed 140). Tovrstne oblike okvirjanja literarnih pravljic, ki so tipične za prve literarne pravljice francoskega salonskega gibanja in ki jih uvajajo posvetila in predgovori, zaključujejo pa končne opombe v obliki pojasnil in pripisov, imajo tudi svojo teoretsko podstat. Pojasnjujejo namreč ne le okoliščine nastanka vsake pravljice, temveč predvsem namen in funkcijo zgodbe, $s$ katero njene avtorice in avtorji vstopajo $\mathrm{v}$ takratne filozofske in politične razprave širšega dometa. Tako na primer Perrault v predgovoru k svoji prvi pravljici v verzih, "Grizeldi« (podobno kot Marie-Jeanne L'Héritier v »Marmoisan«), izpostavlja, da pravljice, nova oblika pripovedi, niso nepomembne in obrobne drobtinice ter zanemarljive muhe enodnevnice ali t. i. bagatelles (Perrault, "Preface" 114). Nasprotno, to naj bi bile zgodbe, ki v jedru nosijo pomemben moralni poduk, $s$ katerim prekašajo tudi antične povesti in so zato poučno čtivo, pomembno za vseživljenjsko vzgojo aristokracije in predvsem za naturalizacijo razlik med aristokracijo in ostalim prebivalstvom. Aristokracija, tako Perrault, naj bi se zlasti od kmečkega življa ločila po domnevni naravni večvrednosti in s tem moralni nadpostavljenosti, ki jo je treba neprestano gojiti tudi med odraslimi, saj naj bi prav slednja potrjevala pravico aristokratskih krogov do vladavine in oblasti nad drugimi (Perrault, "Dedicatory Letter" 126). Pravljice naj bi, kot izpostavlja Perrault, predstavljale enakovreden doprinos $h$ krepitvi vloge aristokracije podobno kot antične moralne povesti. Prav njegove pravljice pa naj bi antične $v$ tem pogledu celo presegale, še zlasti kar zadeva naravo moralnih podukov, ki jih Perrault v svojih pravljicah namenja aristokratskim ženskam. To naj bi ne nazadnje izkazovala že njegova prva pravljica v verzih, tj. Grizelda (Perrault, "Preface« 116).

$\mathrm{V}$ paratekste, ki okvirjajo in teoretično pojasnjujejo okoliščine nastanka in pomen pravljic, so vstavljeni še drugi tehnični elementi: avtorice in avtorji namreč vanje vpletajo tudi reference na literarne predloge. Te ne služijo le kot vir navdiha, ampak predvsem kot izhodiščni narativni vzorec, na katerem gradijo svoje pripovedi: v te vzorce vgrajujejo nove podtone s podobno ali isto izhodiščno tematiko in motiviko ter celo isto, le nekoliko spremenjeno ali nadgrajeno dogajalno nitjo oziroma njenimi deli, kot jih je mogoče zaslediti v literarnih predlogah preteklih epoh, ki jih omenjajo ali pa se nanje neposredno sklicujejo. Za 
enega izmed poglavitnih literarnih virov poleg Basilejeve zbirke Zgodbe vseh zgodb velja prav Straparola in njegova zbirka Prijetne noči, ki je na francosko govoreče območje prešla tudi s prevodom Jeana Louveauja leta 1560 pod naslovom Les facetieux nuits (Bottigheimer, Fairy Tales Framed 103). Mme de Murat na primer v pripisu ali opombi k zbirki Histoiries sublimes et allégoriques (Sublimne in alegorične pripovedi, 1699) zapiše, da si je kot ostale salonske avtorice idejo za pravljice v tej zbirki pripovedi izposodila neposredno pri Straparoli in njegovi zbirki zgodb Prijetne noči. Ta je bila na Francoskem, kot še pojasnjuje, že na prehodu v 17. stoletje izjemno priljubljena, saj je do leta 1615 izšlo kar šestnajst prevodnih ponatisov, zadnji pa 1699 (Bottigheimer, Fairy Tales Framed 204).

Če si podrobno ogledamo te literarne izposoje, predelave in priredbe, $s$ tem pa odtise Basilejevih in Straparolovih zbirk pripovedi na primer v danes klasičnih literarnih pravljicah Charlesa Perraulta, se te kažejo že v njegovi prvi zbirki treh pravljic v verzih. Perrault je to zbirko objavil leta 1695 pod naslovom Contes en vers (Pripovedi v verzih). Prva, "Potrpežljiva Grizelda«, ki jo je že leta 1691 prebral in predstavil na francoski akademiji (Saupé in Collinet 53), je po motiviki predelava Boccaccieve "Grizelde", zadnje povesti v Dekameronu. Ta se je, kot izpostavlja Bottigheimer, nato prek Petrarke in njegovega prepoznavnega mizogino obarvanega prevoda v latinščino v tej obliki razširila po Evropi (Bottigheimer, Fairy Tales Framed 113). Na območju Francije je bila v času salonskega gibanja prav ta Basilejeva literarna predloga dobro znana tudi v drugi, poenostavljeni obliki. Med prebivalstvom je namreč krožila kot sestavni del t. i. Modre knjižnice (Bibliothéque bleue), na stran katere se je postavil Perrault v sporu z zagovorniki antičnega pisanja (Saupé in Collinet 53).

Druga Perraultova pravljica v prvi zbirki, »Oslovska koža«, je neposredna predelava dveh zgodnejših literarnih predlog, in sicer Straparolove "Doralice«, včasih naslovljene tudi kot "Tebaldo po očetu", ki se pojavlja v pripovedi (četrte pripovedi prve noči), in Basilejeve "Medvedke" (Bottigheimer, Fairy Tales Framed 121; Zipes, The Great v). Obe izhajata iz še starejšega rimsko-antičnega vira, tj. Apulejevega Zlatega osla, v katerem se pripovedovalec zaradi čarovnije po nesreči prelevi v osla in je $\mathrm{v}$ tej pojavni obliki priča ugrabitvi mlade neveste, za katero njeni ugrabitelji sklenejo, da jo bodo pokončali tako, da bodo osla odrli, njo pa zavili v oslovsko kožo. Straparolova in Basilejeva verzija temeljita na motivu incestnega, nasilnega očeta, ki ga obe verziji obsodita. Žrtvama se $s$ pomočjo nekdanje varuške in nadomestne matere ali pa starejše služabnice uspe ubraniti očeta in seksualnega nasilja, ki ga uteleša, pri čemer 
Basilejeva protagonistka prevzame podobo medvedke. Še več, izvijeta se iz očetovega primeža in se poročita z izbrancema. Straparola očeta, ki še naprej preganja in ogroža hčer, za kazen pokonča. Perraultova predelana verzija, ki združuje vse ključne elemente predhodnih literarnih pripovedi, pa ga v izteku, ravno nasprotno, v skladu s patriarhalno paradigmo, ki jo je zagovarjal v sporu o ženskah, povsem opere vsakršne krivde (Tartar 129). Tudi tretja pravljica v Perraultovi prvi zbirki, »Smešne želje» (Les Souhaits ridcules), ki jo je avtor javnosti predstavil že novembra 1693 (Saupé in Collinet 53), temelji na primer na vgradnji in predelavi enega od seksualno eksplicitnih motivov, ki jih najdemo v Basilejevi pripovedi o gozdarju in njegovi ženi (Bottigheimer, Fairy Tales Framed 122-123). Podobno velja za Perraultovo drugo in osrednjo zbirko osmih pravljic v prozni obliki Poučne zgodbe in povesti iz preteklosti (Histoires ou contes du temps passé, avec des moralités, 1697), ki danes tvorijo jedro kanona klasičnih literarnih pravljic. ${ }^{6}$

Kot izpostavljajo številni literarnozgodovinski raziskovalci in raziskovalke z Ruth Bottigheimer, Jackom Zipesom in Marino Warner na čelu, se tudi te pripovedi neposredno napajajo pri Straparolovih in predvsem Basilejevih literarnih predlogah: po njih se ne le zgledujejo, ampak si neposredno izposojajo "tako motiviko kot posamične epizode in celo potek dogodkov ali dogajalno premico" (Bottigheimer, Fairy Tales: A New History 57). ${ }^{7}$ Od vseh osmih pravljic, ki jih prinaša

${ }^{6}$ Perrault je najprej leta 1695 pripravil rokopis zbirke petih pravljic (»Trnuljčica«, "Rdeča kapica«, "Sinjebradec«, "Obuti maček« in »Vile«), ki jo je posvetil Élisabeth-Charlotte d`Orléans, devetnajstletni nečakinji Ludvika XIV. (Bottigheimer, Fairy Tales Framed 65). Nato ga je dopolnil s tremi pravljicami: „Pepelka«, "Grbavec s čopkom" in "Palček". Pod leta 1697 objavljeno zbirko pa je kot avtorja podpisal svojega sina, Pierra Perraulta Darmancourja (Saupé in Collinet 53).

7 Perraultov "Obuti maček» je - tako po poteku dogajanja kot motiviki (ne pa tudi vsebinski poanti) - identična preslikava zgodnejših literarnih predlog Straparolove pripovedi "Constantino Fortunato« in Basilejeve "Cagliuso« (Zipes, The Great vi). Trnuljčica je predelava Basilejeve pripovedi "Sonce, Luna in Talia» (Sole, Luna e Talia) in črpa iz viteške arturijanske romance "Perceforest« iz zgodnjega 16. stoletja (Warner 220). V nasprotju s Perraultovo verzijo, ki pasivnosti osrednje junakinje in herojstvu njenega rešitelja nadene drugačen, romantičen predznak, Basilejeva verzija obravnava spolni napad: nezavestno mladenko v njenem gradu na enem od lovskih pohodov odkrije že poročeni kralj in jo zlorabi; čez devet mesecev ta rodi dvojčka in vse začne preganjati kraljeva prva, zakonita žena. Tudi »Pepelka« je predelava Basilejeve pripovedi "La Gatta Cenerentola", v kateri ne najdemo steklenega čevlja, marveč leseno galošo. Prav tako ni govora o pasivni in trpeči ter od vseh zatirani junakinji, marveč o premeteni spletkarki. Zavoljo lastne koristi dekle pomaga guvernanti, da se poroči z njenim očetom, tako da umori očetovo drugo ženo, ki mlado dekle zapostavlja: na predlog guvernante ji na glavo s treskom povezne pokrov skrinje. Tudi v primeru Vil 
Perraultova osrednja in danes kanonizirana zbirka, le "Rdeča kapica» ne izhaja iz literarnih predlog predhodnih avtorjev oziroma književnih zvrsti in literarnih tradicij zgodnejših obdobij, marveč je edina $v$ celoti predelava francoske ljudske pripovedi, znane kot "Zgodba o stari materi« (glej Zipes, The Trials).

\section{Srednjeveški viteški in pastoralni roman}

Če za Perraulta in vse ostale prve pravljičarke velja, da so neposredno črpali_e iz literarnih predlog Straparole in Basileja, velja tudi, da so se pri snovanju prvih literarnih pravljic istočasno naslonili_e še na druge literarne vire in žanre, še zlasti na srednjeveški in zgodnjerenesančni obliki pastoralnega oziroma pastirskega in viteškega romana. Poglavitni vir navdiha so za Perraulta poleg anonimnega Perceforesta predstavljali viteški romani izpod peresa Chrétiena de Troyesa (Lancelot; Yvain ali vitez $z$ levom) in pripovedne pesmi Marie de France, ki opevajo dvorsko ljubezen (Saupé in Collinet 53). Za avtorice pa so bili vir navdiha in motivnih predelav tudi Roman o Tristanu in Izoldi, Ariostov viteški ep Besneči Orlando, legenda o Merlinu in legenda o Melusini (Cheira 225). Francoske salonske pravljičarke in pravljičarji so namreč novele spojili z njim nasprotnim žanrom, tj. srednjeveškimi pastoralnimi in viteškimi romani. Tako so novi pravljični žanr lahko opremili_e z vsebino, ki zagovarja aristokratski družbenoekonomski red. Pripovedi so zato naselili in prepredli izključno $\mathrm{z}$ aristokratskimi nosilci osrednjega narativnega dogajanja, tj. $s$ kralji in kraljicami, princesami in princi, ter novi žanr prilagodili okusu in približali pogledu aristokratskega občinstva, kateremu so bile pravljice prvotno namenjene (prim. Seifert, Fairy). Temeljne značilnosti viteškega romana, ki jih prevzemajo tudi prve pravljice, vključujejo ljubezensko tematiko $s$ poudarkom na junaštvu vitezov; da bi si pridobili naklonjenost dame, se ti podajajo $\mathrm{v}$ neverjetne avanture. Toda te jih popeljejo zgolj od enega do drugega dvora, zato je temu tipu romana, znanemu tudi kot dvorni roman, lastno predvsem to, da gre za podvajanje tipskih družbenih postavitev

je Perrault črpal iz Basilejeve pripovedi »Tri vile» (Tre fate) in »Le due Pizzette«, opirajoč se hkrati na že predelano verzijo njegove nečakinje Marie-Jeanne L'Héritier »Les Enchantements d`éloquence«, ki je navdih našla v taisti Basilejevi literarni predlogi (Bottigheimer, Fairy Tales Framed 65). Tudi v Perraultovem "Sinjebradcu" eden od ključnih momentov pripovedi izhaja iz Basilejeve literarne predloge "Tri krone» (Le tre corone): tj. trenutek, ko Sinjebradec ob odhodu z gradu preda ključe soban mladi nevesti in ji prepove, da bi pogledala v zadnjo dvorano na koncu hodnika. 
dvornega aristokratskega reda, za katere se zdi, da so samozadostne in samonarojene in da so zato brezčasne, statične ali tipsko enake v svoji umetni ločenosti od vsega ostalega, pa čeprav ključnega družbenega okolja, in s tem od življenja slehernika. Ta značilnost se ponavlja tudi v pastoralnih ali pastirskih romanih, ki so izvorno izpeljave antičnih predlog, zlasti Vergilovih bukoličnih pesnitev (Kos 116). V pastirskih ali arkadijskih romanih je - po vzoru antičnih predlog, v katerih nastopajo pastirji, bogovi in osrednji junaki izključno plemenite krvi - dogajanje postavljeno $\mathrm{v}$ idilično naravo in $s$ tem umetno odmaknjeno od družbenega reda. Za idilično ali bukolično naravo, tj. Arkadijo, se zdi, da je ne zaznamujejo za novele značilne sledi družbenega reda kot tudi ne tukajšnjost in zdajšnjost družbenega časa. Tudi tu sta čas in z njim družbena ureditev neotipljiva, večno ista in med seboj zamenljiva. Poudarek je zato izključno na ljubezenskih zapletih in prepletih ter navidezno nedovoljeni ljubezni med pripadniki aristokracije, dinamika katere izhaja iz sprva navidezno različnih stanov enega od obeh protagonistov. Za osebo, ki se zaradi spleta okoliščin znajde zunaj družbe v objemu narave, kjer jo vzgajajo pastirji, se v srečnem razpletu zgodbe izkaže, da je, v nasprotju z njenimi krušnimi starši, aristokratskega rodu. Zato je $\mathrm{v}$ izteku njena poroka $\mathrm{z}$ izbranim ljubimcem navidezno višjega stanu upravičena in dovoljena, osebi pa je, ob razkritju njene prave identitete, povrnjen aristokratski status in s tem premoženje in bogastvo, ki ji pripadata po stanu in nasledstvu.

Vse ključne značilnosti obeh podzvrsti srednjeveških romanov, tj. neotipljivost prostora in časa, odrezanost od družbenih razmer in zaprtost aristokracije $\mathrm{v}$ samozadostni krog ter hkrati restavratorski vzorec, po katerem so osebe plemenitega rodu ponovno povrnjene na svoje družbeno mesto, so sestavni in določujoči elementi pravljice kot novega žanra. Varna odmaknjenost prostora in časa, ki je odrezan od prepoznavnih potez sodobnega časa in njegovih družbenih umestitev, hkrati pa njuna večna nespremenljivost ali tipska statičnost se odražajo v prepoznavni formuli »nekoč je živel/a» ali »nekoč je bil/a». To je formula, ki zaznamuje začetek vsake pravljice in ki jo je uveljavilo francosko literarno salonsko gibanje ${ }^{8}$ po zgledu literarnih predlog pastoralnega in viteškega romana: neotipljivost, ki jo predstavljata izraz "nekoč» kot

${ }^{8}$ Kot je na podlagi ohranjenega rokopisnega materiala ugotovila Ellen Welch, se je Perrault v svojih pravljicah nagibal k verziji »Il état une fois«, medtem ko so pravljičarke z Mme Murat na čelu raje uporabljale izraza "Il y avait une fois« in "Il y eut autrefois« (2). Teh razlik v slovenskem prevodu ni mogoče ohraniti. Kljub temu gre $\mathrm{v}$ vseh treh oblikah in primerih za nedoločljivost in neotipljivost prostora in časa, ki ju predpostavlja nedovršni glagolski čas (Thelander 484). 
tudi geografska nedorečenost "za devetimi gorami«, pravljično pripoved postavlja $\mathrm{v}$ varno oddaljeno preteklost ali nespecifičnost časa in prostora (Thelander 484), brez prepoznavnih zgodovinskih potez vsakdana kot tudi individualnih značajskih potez njenih protagonistov. Postavlja jo v čas in prostor, ki sta oba nespecifična in večna, neobremenjena $\mathrm{z}$ družbeno problematiko in realnostjo vsakdana. To je prostor, ki ga poseljujejo protagonisti plemenitega aristokratskega rodu, zapleteni v svoje intrige, padce in vzpone, ki zadevajo ozki in zaprti krog ljudi. Zato je po zgledu pastoralnih romanov osrednji tip pripovedi takšen, da srečni zaključek temelji na povrnitvi izgubljenega ali odvzetega kraljestva, že prej pripadajočega bogastva in aristokratskega statusa osrednji protagonistki ali protagonistu, kar vodi v obnovitev ali razširitev rodbinskega bogastva kot tudi k utrditvi statusa pravičnega in dobrega vladarja v nasprotju z nepravičnim in tiranskim. Vzorec, ki ga pravljice prevzemajo iz viteških in pastoralnih romanov, da bi utrdile in naturalizirale aristokratski fevdalni red, stoji v ostrem nasprotju z vrsto pripovedi v Straparolovi in Basilejevi zbirki novel (Bottigheimer, Fairy Tales: A New History 25, 94). ${ }^{9}$ Osrednji motiv, ki pripovedi daje okvir, temelji na izvitju slehernika iz primeža revščine in napredovanju po socialni lestvici, s tem pa pridobitvi uglednega položaja in bogastva, ki mu kot siromaku ali kako drugače družbeno deprivilegirani osebi sicer ne pripadata.

\section{Elementi magičnega: dobre vile}

V svoje večinoma restavracijske pripovedi, ki zagovarjajo aristokratsko družbeno ureditev in fevdalni red, so avtorice prvih literarnih pravljic vgradile tudi magičnost, saj so pripovedi prepletle z nadnaravnimi

\footnotetext{
${ }^{9}$ Straparolov tip pripovedi - po katerem se tistim, ki so rojeni v revščino, uspe povzpeti po družbeni lestvici - se je prebil v ospredje pravljičnega literarnega kanona šele po francoski revoluciji leta 1789 (Bottigheimer, Fairy Tales Framed 4), ob nastopu kapitalističnega reda in pojavu t. i. srednjega razreda. Za siromake seveda ne veljajo pripadniki resnično izkoriščanega razreda kmetov in delavcev, marveč obrtniki, trgovci in drugi malomeščani, tj. predstavniki srednjega stanu. Najprepoznavnejši vzorec $\mathrm{v}$ tem tipu pripovedi, ki jo je uvedel Straparola, je, da se siromaku uspe izviti iz primeža revščine s pomočjo poroke in bogastva, ki ga prinaša zakon z osebo iz aristokratskega, premožnega sloja. To je bilo seveda v nasprotju z realnostjo, zavoljo česar so Straparolove pripovedi tega tipa delovale kot utopija, oblika upanja in uspavalo za množice revnih v Benetkah, kjer so bile poroke med mestno aristokracijo in običajnimi smrtniki prepovedane po zakonu iz dvajsetih let 16. stoletja (Bottigheimer, Fairy Tales: A New History 21).
} 
elementi in motivi, ki so si jih izposodile deloma iz antične mitologije, deloma pa iz ljudskega pripovedništva (Seifert, Fairy 33). Če je mogoče nekaj magičnih elementov zaslediti že v Straparolovi zbirki novelističnih pripovedi, je za prve literarne pravljice značilno, da v ospredje postavijo magičnost ali nadnaravnost. Uvedejo bogat nabor najrazličnejših magičnih bitij (kot so velikani, ljudožerci, škrati, prerokinje in čarovniki) in čudežnih pripomočkov (kot so čarobne palice, prstani in drugi čudežni predmeti), $s$ katerimi protagonisti lahko brez težav premagujejo velike razdalje ali spreminjajo pojavno obliko. To spreminjanje je lahko sestavni del prekletstva in s tem preizkušenj, ki jih morajo prestati protagonisti, ali pa oblika dobronamerne pomoči, ki jim omogoča, da uspešno premagajo najrazličnejše ovire na poti k cilju (Duggan 234). Te oblike magičnega so si avtorice izposodile iz ljudskega pripovedništva, in sicer iz posebne vrste ljudske pripovedi, tj. čudežne pripovedi. V njej čudežno ali magično, kot izpostavlja Seifert, utelešajo antropomorfne živali, velikani, velikani ljudožerci in druga magična bitja, ki nastopajo kot protagonistovi pomočniki ali pa se mu zoperstavljajo in ga ovirajo na njegovi poti k cilju. Naloga teh bitij je, da v svoji pozitivni ali negativni vlogi protagonistu napovedo prihodnost in jo vnaprej določijo; $\mathrm{da}$ nastopajo $\mathrm{v}$ vlogi svetovalk in svetovalcev, da na protagonistovo pot postavijo najrazličnejše ovire, ki po eni strani upočasnijo njegovo napredovanje ali ga povsem onemogočijo, na drugi pa mu pomagajo pri premagovanju ovir. Pri tem mu v trajno last izročajo najrazličnejše predmete $\mathrm{z}$ magičnimi lastnostmi ali pa mu v ključnem trenutku na pomoč prihitijo v svoji naravni podobi (Seifert, Fairy 33). Vseskozi gre za ohranjanje in naturalizacijo fevdalnega reda, saj je osrednja naloga tovrstnih magičnih oseb, ki jih odlikujejo nadnaravne sposobnosti in lastnosti, da v izteku pripovedi vnovič vzpostavijo aristokratski red, največkrat prav na račun povrnitve nesrečno izgubljenih ali z zvijačo odtujenih kraljestev osrednjim protagonistom (Seifert, Fairy 34), kar deluje kot svojevrstna oblika aristokratske restavracijske pripovedi.

Med magičnimi bitji v prvih salonskih pravljicah, zlasti tistih izpod peresa avtoric, prednjačijo vile (Seifert, Fairy 197), ki v nasprotju s srednjeveškimi renesančnimi vilami rojenicami prevzemajo nove, razširjenje in vsestranske funkcije. $\mathrm{V}$ srednjeveških in renesančnih pripovedih vile, katerih poimenovanje $\mathrm{v}$ francoščini (fée), italijanščini (fata) in španščini (hada) izhaja iz latinske besede fata ali boginja usode (Seifert, Fairy 198), prvotno nastopajo v vlogi vil rojenic ali družinskih boter: njihova naloga je, da napovedo usodo novorojenca ali novorojenke in ga obdarijo z magičnimi darili ali sposobnostmi, pri čemer prerokbo dobre vile za nekaj časa izniči protiprerokba slabe vile. V 
prvih literarnih pravljicah izpod peres francoskih salonskih avtoric in avtorjev se vile pojavljajo na vsakem protagonistkinem koraku: $s$ svojim znanjem in nadnaravnimi močmi ji vseskozi pomagajo, jo zasipavajo $\mathrm{z}$ darili in materialnimi dobrinami (tudi v obliki skrite dote) in ji pomagajo premagovati najtežje ovire, ki ji jih na pot postavljajo drugi ljudje. Delujejo kot druge matere, a na način, da v svoji magičnosti, nadnaravnosti in neizmerni moči presegajo tako biološko smrtnost kot primež zakonskih zvez, ki zaznamujejo in onemogočajo delovanje dejanskih bioloških mater. Zato so neusahljiv in nezlomljiv vir medsebojne ženske solidarnosti, moči in avtoritete (Seifert, Fairy 196, 199). Prve literarne pravljice, ki so nastale v okviru francoskega salonskega gibanja predvsem izpod peres francoskih salonskih avtoric, so prepredene z vilami, ki predstavljajo prevladujoči in osrednji tip magičnih nadnaravnih bitij. Ne nastopajo le kot osrednje pomočnice, marveč tudi kot ene izmed nosilk pripovedi: vedno poskrbijo za srečen zaključek, ki deluje v korist protagonistke in njenih sester (ter širše kraljevske rodbine) ne glede na njihovo razvajenost, sebičnost in škodoželjnost. Osrednja protagonistka tovrstne nelaskave značajske lastnosti svojih sester ne le potrpežljivo prenaša, marveč jim v zaključku kot znak svoje aristokratske dobre vzgoje in omike vsa njihova grda dejanja tudi odpusti, sestre pa se vse tudi bogato poročijo. Rešitev protagonistke iz zagate in praviloma srečen konec, ki temelji tudi na povrnitvi izgubljenega kraljestva in $s$ tem aristokratskega statusa, ni odvisna od princa rešitelja, marveč vseskozi od modrega in vzajemnega delovanja vile botre in princese protagonistke. Srečen konec je odvisen od znanja in nadnaravnih lastnosti zaščitnice protagonistke, tj. vile botre, do katere ima protagonistka spoštljiv in prijazen odnos, kar ji tudi zagotavlja naklonjenost in zanesljivo pomoč druge, nadomestne matere. Prav zato, ker so prve literarne pravljice prepredene $\mathrm{z}$ vilami, so avtorice svojim prvim objavljenim zbirkam pravljičnih pripovedi nadele ime contes de fées, kar pomeni pripovedi vil, včasih pa tudi contes des fées, kar pomeni pripovedi o vilah (Warner 234). Nova žanrska pripoved ali tip pripovedi je tako dobila ime, ki se je $\mathrm{v}$ francoščini in angleščini (fairy tales) ohranilo do danes. Vpeljali in uveljavili sta ga Marie-Catherine d'Aulnoy - ta je leta 1697 svojo prvo zbirko štirih knjig naslovila Les contes des Fées (Pripovedi o vilah), svojo drugo zbirko prav tako štirih knjig pa Contes nouveaux ou les Fées à la mode (Nove pripovedke ali pravljice po modi, 1698) - in Henriette-Julie Murat, ki je svojo prvo zbirko naslovila Contes de Fées (Pripovedi vil, 1697), drugo iz leta 1698 pa Les Nouveaux Contes des Fées ali Nove pripovedi o vilah (Patard 85; Jasmin 64; Hannon in Duggan 379). 
V literarne pravljične pripovedi so avtorice vpele še drugo obliko magičnega, ki izvira iz antičnih literarnih predlog oziroma antične mitologije. Gre za obliko magičnega, povezanega z nadnaravnimi močmi božanstev in bogov, zato $\mathrm{v}$ njihovih delih najdemo tudi obliko božanske nadnaravnosti in $s$ tem magičnosti, ki jo utelešajo rimski in grški bogovi, kot sta Jupiter in Kupid, ali polbogovi in druga podporna božanska bitja kot na primer Zefir (Seifert, Fairy 33). Vse te elemente, ki z drugimi literarnimi vpisi - predvsem odtisi renesančnih in srednjeveških literarnih predlog - določajo osnovne prvine novega pravljičnega žanra, najdemo v prvi literarni pravljici »Otok sreče» (L'Ile de la Félicité), ki jo je leta 1690 objavila Marie-Catherine d'Aulnoy. Umestila jo je v svoj roman z naslovom Historie d'Hypolite, comte de Douglas, ki služi kot okvirna pripoved po vzorcu, ki ga je zasnoval Boccaccio, nadaljevala pa Straparola in Basile. Pravljica se odvija med dvema svetovoma, minljivim zemeljskim, $\mathrm{v}$ katerem domuje ruski princ Adolf, in vilinskim, ki mu vlada vila princesa. Mladi ruski princ se na lovu na medveda pred neurjem zateče $v$ jamo, kjer naleti na Kupida, ki mu pove zgodbo o magičnem vilinskem otoku, kjer je življenje kot v raju. Princ prepriča Zefirja, Zahodni veter, da ga ponese na ta vilinski otok, kjer vilinski princesi pokloni svoje srce. Srečnemu zakonskemu življenju navkljub princa premagajo skomine po zemeljskemu življenju oziroma statusu in časteh, ki mu kot bodočemu vladarju Rusije pripadajo v njegovem zemeljskem kraljestvu. Vilo, vladarico otoka, zapusti in se poda nazaj v svoje kraljestvo. Kljub temu da se princ izneveri ljubezni do vile in jo celo zavrže $\mathrm{v}$ prid lastnim ozkim zemeljskim interesom, ga ta iz ljubezni zaščiti pred smrtjo, ki mu sicer grozi takoj ob prehodu nazaj v zemeljski svet, saj je na vilinskem otoku nevede dopolnil že tristo let. Naroči mu, da ne sme nikoli razjahati vilinskega konja, kajti dokler bo $\mathrm{v}$ njegovem sedlu, ga bo ta z nadnaravnimi močmi ščitil pred človeško umrljivostjo. Po prihodu nazaj v svoj svet princ naleti na starčka, ki leži ukleščen pod prevrnjenim vozom, in mu poskuša pomagati, zato razjaha. Izkaže se, da gre za zvijačo: starček je bog vetra in smrti, ki se oprime princa in ga ne izpusti iz rok, zato je obsojen na smrt. Pravljica ima distopični zaključek (Bottigheimer, Fairy Tales Framed 167): junak postane del vilinskega sveta in s tem srečnega življenja na otoku vilinske sreče, krona katerega je srečna, vzajemna ljubezen. Tej se odpove, da bi se vrnil v minljivi človeški svet materialnih interesov, zato ga za kazen čaka smrt. Pravljica je oblika politične alegorije in komentarja, saj kot vse prve pravljice francoskega salonskega gibanja podpira zahteve salonskih aristokratinj po svobodni in vzajemni ljubezni namesto prisilnih porok in zato po ljubezni, ki se ji ne gre izneveriti. 


\section{Zaključek}

Prve literarne pravljice, ki so $\mathrm{v}$ danes prepoznavni žanrski obliki vzniknile ob koncu 17. stoletja v okviru francoskega salonskega gibanja, so oblika žanrske zmesi, zaznamovane tako z odtisi kot neposrednimi izposojami in predelavami motivov in strukturnih zakonitosti predhodnih, že uveljavljenih literarnih zvrsti, zlasti renesančne italijanske novele in srednjeveškega viteškega in pastirskega romana, z dodatki antične mitologije in elementi magičnega iz ljudskega pripovedništva. Ta njihova literarna zaznamovanost, vključno $s$ parateksti, je bila na prehodu v romantično 19. stoletje načrtno izbrisana, da bi se lažje ustvarilo in zakoreninilo predstavo, da so literarne pravljice le oblika zapisa ljudskega pripovedništva; obe zvrsti pa naj bi imeli pradavne in enotne korenine, kar naj bi pričalo o skupnem in kontinuiranem razvoju novonastalih nacionalnih skupnosti, njihovemu izvoru pa naj bi bilo mogoče prav tako zlahka slediti že v pradavnino. ${ }^{10}$ Romantično gibanje je tudi prineslo koncept ločenosti otroštva od odraslega sveta in $s$ tem institut nedolžnega, družbeno nezaznamovanega otroštva ter $\mathrm{v}$ povezavi $s$ tem novo knjižno polje: književnost za otroke. Ta v 17 . stoletju, ko so nastale prve literarne pravljice, namenjene odraslemu občinstvu literarnih salonov, še ni obstajala. Romantično gibanje je tako prineslo tudi predstavo, da naj bi bile pravljice primarno mišljene kot oblika pripovedi za otroke, in le posredno za odrasle. Literarna zgodovina dokazuje ravno obratno: z izjemo Magasin de enfants (1756) avtorice de Beaumont so se prve priredbe literarnih pravljic za otroke pojavile šele v 30. letih 19. stoletja (Bottigheimer, Fairy Tales: A New History 40), in sicer kot del projekta, s katerim sta brata Grimm želela $s$ krajšo, prilagojeno različico za otroke promovirati svojo zbirko pravljic, ki je bila mišljena za odrasle (Zipes, When Dreams). Priredbe so se kot čtivo za otroke pojavile množično v drugi polovici 19. stoletja, ko so postale del šolskega kurikuluma, in sicer najprej prav na Nemškem, kjer naj bi prispevale k izgradnji predstave o skupni pradavni nacionalni pripadnosti nedavno združenih nemško govorečih dežel (Bottigheimer, Fairy Tales: A New History 55). Predstava o pravljicah, ki naj bi bile ustvarjene prvotno za otroke, od vsega začetka pa le preslikava ljudskega izročila v pisni obliki, je mit, ki ga je ustvarilo romantično gibanje 19 . stoletja.

${ }^{10}$ Glej npr. Grimm in Grimm, »Vorrede«; Lee M. 27-50; Snyder, "Cultural«; Snyder, »Nationalistic«; Haase, »Your«; Haase, Reception; Bottigheimer, »Fairy Tales». 


\section{LITERATURA}

Beale, Hazel. »Framing the Fairy Tale: French Fairy Tales and Frame Narratives 1690-1700«. Framed! Essays in French Studies. Ur. Lucy Bolton idr. Oxford; Bern: Peter Lang, 2007. 73-90.

Bottigheimer, Ruth. Fairy Tales Framed: Early Forewords, Afterwords, and Critical Words. Albany: SUNY Press, 2012.

Bottigheimer, Ruth. "Fairy Tales". Encylopedia of German Literature. Ur. Matthias Konzett. Chicago: Fitzroy Dearborn, 1999. 267-270.

Bottigheimer, Ruth. Fairy Tales: A New History. Albany: SUNY Press, 2009.

Brocklebank, Lisa. "Rebellious Voices: The Unofficial Discourse of Cross-dressing in d'Aulnoy, de Murat, and Perrault«. Children's Literature Association Quaterly 25.3 (2000): 127-136.

Cheira, Alexandra. "A Fairy Godmother of her own 17th Century France: Subversive Female Agency in Madame d'Aulnoy's 'The White Cat'«. Anglo Saxonica 30.8 (2014): 219-240.

Duggan, Anne E. "Conte des feés«. Folktales and Fairy Tales: Traditions and Texts from around the World. Ur. Ann E. Duggan idr. Santa Barbara; Denver: Greenwood, 2016. 234.

Fatur, Silvo. Književnost II. Maribor: Obzorja, 1982.

Feat, Anne-Marie. »Playing the Game of Frivolity: Seventeenth-Century Conteuses and the Transformation of Female Identity«. Journal of the Midwest Modern Language Association 45.2 (2012): 217-242.

Grimm, Jacob, in Wilhelm Grimm. „Vorrede«. Deutsche Sagen. Berlin: in der Nicolaschen Buchhandlung, 1816. v-xxvi.

Haase, Donald. The Reception of Grimms' Fairy Tales: Responses, Reactions, Revisions. Detroit: Wayne State University Press, 1993.

Haase, Donald. „Yours, Mine, or Ours? Perrault, the Brothers Grimm, and the Ownership of Fairy Tales". Merveilles \& contes 7.2 (1993): 383-402.

Hannon, Patricia, in Anne E. Duggan. "French Tales: Origins of the French Tale Tradition". The Greenwood Encyclopedia of Folktales and Fairy Tales. Ur. Donald Hasse. Westport; London: Greenwood Press, 2008. 379-388.

Jasmin, Nadine. "Sophistication and Modernization of the Fairy Tale». Teller's Tale: The Lives of the Classic Fairy Tale Writers. Ur. Sophie Raynard. Albany: SUNY Press, 2012. 41-46.

Jones, A. Christine. "Madame d'Aulnoy Charms the British". The Romanic Review 99.3/4 (2008): 239-256.

Kos, Janko. Književnost: učbenik literarne zgodovine in teorije. Maribor: Obzorja, 1989.

Lee M., Roberts. Literary Nationalism in German and Japanese Germanistik. Berkley Insights into Linguistics and Semiotics 78. New York: Peter Lang, 2010.

Patard, Geneviéve. »Henriette-Julie de Castelnau, Countess de Murat". Teller's Tale: The Lives of the Classic Fairy Tale Writers. Ur. Sophie Raynard. Albany: SUNY Press, 2012. 81-87.

Perrault, Charles. "Preface«. Fairy Tales Framed: Early Forewords, Afterwords, and Critical Words. Ur. Ruth Bottigheimer. Albany: SUNY Press, 2012. 114-118.

Perrault, Charles. "Dedicatory Letter to Mademoiselle (1695)«. Fairy Tales Framed: Early Forewords, Afterwords, and Critical Words. Ur. Ruth Bottigheimer. Albany: SUNY Press, 2012. 126.

Saupé, Yvette, in Jean-Pierre Collinet. „Charles Perrault«. Teller's Tale: The Lives of the Classic Fairy Tale Writers. Ur. Sophie Raynard. Albany: SUNY Press, 2012. 47-59. 
Seifert, C. Lewis. "Marie-Jeanne Lhéritier de Villandon". Teller's Tale: The Lives of the Classic Fairy Tale Writers. Ur. Sophie Raynard. New York: Suny Press, 2012. 75-80.

Seifert, Lewis. Fairy Tales, Sexuality, and Gender in France, 1690-1715: Nostalgic Utopias. Cambridge; New York: Cambridge University Press, 1996.

Snyder, Louis L. "Cultural Nationalism: The Grimm Brothers' Fairy Tales". Roots of German Nationalism. Ur. Louis L. Snyder. Bloomington: Indiana University Press, 1978. 35-54.

Snyder, Louis L. "Nationalistic Aspects of the Grimm Brothers' Fairy Tales». The Journal of Social Psychology 33 (1951): 209-223.

Tartar, Maria. Off with their Heads: Fairy Tales and the Culture of Childhood. Princeton: Princeton University Press, 1992.

Thelander, R. Dorothy. »Mother Goose and Her Goslings: The France of Louis XIV as Seen through the Fairy Tale". The Journal of Modern History 54.3 (1982): 467496.

Touttain, Piere-André. "O pravljicah Mme. d`Aulnoy«. Pavji kralj in druge pravljice. Madame d'Aulnoy. Ljubljana: Mladinska knjiga, 1987. 6-7.

Treverson, Andrew. Fairy Tale. London in New York: Routledge, 2013.

Welch, Ellen. »'Une feé moderne': An Unpublished Fairy Tale by la Comtesse de Murat". Eighteenth-Century Fiction, 18.4 (2006): 1-20.

Zipes, Jack. »The Rise of the French Fairy Tale and the Decline of France«. Beauties, Beasts, and Enchantment: Classic French Fairy Tales. Ur. Jack Zipes. Maidstone: Crescent Moon Publishing, 2009. 1-13.

Zipes, Jack. Breaking the Magic Spell: Radical Theories of Folk and Fairy Tales. Lexington: University Press of Kentucky, 2002.

Zipes, Jack. When Dreams Came True: Classical Fairy Tales and Their Tradition. New York in Abingdon: Routledge, 2007.

Zipes, Jack. The Great Fairy Tale: From Straparola and Basile to the Brothers Grimm. New York: Norton Critical Edition, 2001.

Zipes, Jack. The Trials and Tribulations of Little Red Riding Hood: Versions of the Tale in Sociocultural context. New York; Oxon: Routledge, 1993.

Zipes, Jack. »Media-hyping of fairy tales«. The Cambridge Companion to Fairy Tales. Ur. Maria Tatar. Cambridge: Cambridge University Press, 2015.

Warner, Marina. From the Beast to the Blonde: On Fairy Tales and their Tellers. London: Vintage, 1995. 


\section{The First Literary Fairy Tales of the French Salons: A Hybrid Genre}

Keywords: literary genres / romanticism / fairy tale / hybrid genre / medieval literature / novella / magic

Romantics introduced the notion that fairy tales are mere transcriptions or reworkings of folk tales, whose content they faithfully replicate. Literary history has proven otherwise: fairy tales are a hybrid literary genre that emerged out of the adaptations of basic features of two medieval and late renaissance genres, the Italian novels and medieval (knight and pastoral) romans. Narrative framing was one of the structural features French salon writers took from the Italian novella, to which they added a technique of their own. Fairy-tales were preceded by dedicatory letters and introductions, and followed by afterwords and comments. These paratexts also carried literary references from earlier periods, which served as a source of inspiration for the fairy-tales' authors. From medieval courtly romans the authors took over the archetypal settings of aristocratic courts. These were disconnected from social environment, which resulted in the creation of geo-temporal distancing and static uniformity of the fairy-tale genre. To this generic mixture, the seventeenth-century French salon authors added elements of magic, which they borrowed from classical mythology and a special type of folk tale - a wonder tale with a special focus set on fairies, heroines' surrogate mothers.

1.01 Izvirni znanstveni članek / Original scientific article

UDK 82.0-343

D0I: https://doi.org/10.3986/pkn.v43.i3.06 